\title{
Convincing Image Source
}

National Cancer Institute

\section{Source}

National Cancer Institute. Convincing Image Source. NCI Thesaurus. Code C158782.

Radiologic evidence that supports a diagnosis. 